\title{
Originals
}

\section{Experimental diabetes impairs rat embryo development during the preimplantation period}

\author{
M. Vercheval ${ }^{1}$, R. De Hertogh ${ }^{1}$, S. Pampfer ${ }^{1}$, I. Vanderheyden ${ }^{1}$, B. Michiels ${ }^{1}$, P. De Bernardi ${ }^{1}$ and R. De Meyer ${ }^{2}$ \\ ${ }^{1}$ Physiology of Human Reproduction Research Unit and, \\ ${ }^{2}$ Center of Medical Genetics, University of Louvain, School of Medicine, Brussels, Belgium
}

\begin{abstract}
Summary. Congenital malformations and early fetal losses are still the main complications of diabetic pregnancy. Whether the diabetic state affects the early embryo development during the preimplantation period is not known. To understand better the early steps of embryo growth, we collected the embryonic structures from the uterine horns of pregnant diabetic rats on day 5 of pregnancy. Diabetes was induced by streptozotocin $(50 \mathrm{mg} / \mathrm{kg})$ injection, 7,14 or 21 days before mating. The morphological analysis revealed a lower rate of blastocysts (72\% of all structures) and an increased rate of morulae $(19.5 \%)$ in diabetic rats, compared to control animals ( 86.7 and $7.9 \%$ respectively). Hence, diabetic rats had fewer blastocysts $(5.5 \pm 2.9$ per rat $)$ and more morulae $(1.5 \pm 1.7)$ than control animals $(7.2 \pm 2.7$ and $0.66 \pm 1.2$ respectively). Moreover, blastocysts from diabetic rats had fewer nuclei ( $26.9 \pm 7.3$ per blastocyst) than blastocysts from control animals $(31 \pm 6.1)$. In another set of experiments, subdiabetogenic doses of streptozotocin were admin-
\end{abstract}

istered. In rats injected with $25 \mathrm{mg} / \mathrm{kg}$, neither the glycaemia, nor the morphological aspects of the embryos, nor the number of blastocyst nuclei differed from the control animals. In the animals receiving $35 \mathrm{mg} / \mathrm{kg}$, the glycaemia was increased to approximately twice the control group value. However, the embryonic morphology and the nuclei counting of the blastocysts were similar to those of the fully diabetic group injected with $50 \mathrm{mg}$ of streptozotocin. These results show that experimentally induced diabetes, even of a rather mild degree, affects the embryo development during the preimplantation period. The recovered embryos appear less mature and less developed. This observation raises the possibility that diabetes induced early fetal loss and teratogenesis might, to some extent, be anticipated by environmental factors deleterious to the preimplanted embryo.

Key words: Experimental diabetes, pregnancy, rat, embryo, blastocyst, congenital malformation, implantation.
Major congenital malformations and early fetal losses are still the main risks encountered in diabetic pregnancy [15]. Early growth retardation has been described in fetuses of human diabetic patients, and this observation was linked with a higher incidence of congenital malformations $[6,7]$.

Experimentally induced diabetes in mice or rats has given an opportunity to understand better the multifactorial mechanisms prevailing in the pathogenesis of these severe fetal injuries $[8,9]$. "In vivo" studies showed the teratogenic effect of maternal diabetes, and the protective effect of insulin treatment during early organogenesis [10]. "In vitro" studies, conducted on early somite embryos, lead to the provisional conclusion that several factors (hyperglycaemia, ketone bodies, somatomedin inhibitors) could interplay to produce the observed deleterious effects on organ growth and differentiation [11]. Low glucose levels $[12,13]$ or decreased glucose utilisation [14], as well as low insulin levels [15] may also contribute as teratogenic factors. When most of these "in vivo" and "in vitro" studies focussed attention on the early period of organogenesis, as the critical time for the highest sensitivity to the teratogenic factors, very few works have been devoted to the preimplantation period. However, considerable morphologic and functional events cause differentiation during the early embryo development $[16$, 17]. Chemical insults to the developing preimplanted embryos may result in early loss, late resorption, retarded morphogenesis, malformed offspring or shorter survival $[18,19]$. The influence of a maternal metabolic dysregulation, like diabetes mellitus, on preimplanted embryo development is so far unknown. In a strain of spontaneously diabetic Chinese hamsters, no deleterious effect of maternal diabetes was reported on preimplanted embryos [20]. In "in vitro" studies, Zusman et al. [21, 22] observed a deleterious effect of ketone bodies, glucagon, high insulin levels or human diabetic serum on the development of preimplanted mouse embryos. Recently, Diamond et al. [23] reported a delay in oocyte maturation in diabetic mice, and an "in vitro" developmental delay of twocell embryos recovered from superovulating diabetic mothers. In "in vivo" studies of streptozotocin-induced 
Table 1. Morphological stages of embryos from day five pregnant control and diabetic rats $(50 \mathrm{mg}$ streptozotocin $/ \mathrm{kg}$ ) (mean $\pm \mathrm{SD}$ )

\begin{tabular}{lcc}
\hline & Control rats & Diabetic rats \\
\hline Number of rats & 44 & 26 \\
Glycaemia (mmol/l) & $5.4 \pm 1.15$ & $23.1 \pm 5.72^{\mathrm{b}}$ \\
Number of structures & 368 & 200 \\
\% of blastocysts & 86.7 & $72^{\mathrm{a}}$ \\
$\%$ of morulae & 7.9 & $19.5^{\mathrm{a}}$ \\
$\%$ of others & 5.4 & 8.5 \\
\hline
\end{tabular}

$p<0.01$ with control rats $\left(\chi^{2}\right.$ test $)$

b $p<0.001$ with control rats (unpaired $t$-test)

Table 2. Pattern of embryonic structures in individual day five pregnant control and diabetic rats (50 mg streptozotocin) (mean \pm SD)

\begin{tabular}{lll}
\hline & Control rats & Diabetic rats \\
\hline Structures/rat & $8.4 \pm 2.4$ & $7.7 \pm 2.5$ \\
Blastocysts/rat & $7.2 \pm 2.7$ & $5.5 \pm 2.9^{\mathrm{a}}$ \\
Morulae/rat & $0.66 \pm 1.2$ & $1.5 \pm 1.7^{\mathrm{a}}$ \\
Others/rat & $0.45 \pm 1.1$ & $0.6 \pm 1.3$ \\
\hline
\end{tabular}

${ }^{a} p<0.05$ with control rats (unpaired $t$-test)

diabetic rats, we observed a $20 \%$ lower rate of implantation sites in diabetic rats compared to control animals, after normal ovulatory cycles [24]. Oestrogen receptor levels were lower in the endometrium of diabetic animals, mainly at the implantation sites [24]. In view of these latter observations, we studied, "in vivo", the morphological development of preimplanted blastocysts recovered from diabetic rats after spontaneous ovulation and mating.

\section{Materials and methods}

\section{Induction of the diabetic state}

Three-month-old female Wistar rats were obtained from the Faculty breeding centre (Université Catholique de Louvain, Brussels, Belgium). Diabetes was induced in these animals, weighing about $200 \mathrm{~g}$, by i. v. injection of streptozotocin (STZ) (Upjohn, Kalamazoo, Mich, USA) as previously described [25,26]. A dose of $50 \mathrm{mg} / \mathrm{kg}$ of body weight was used to produce a permanent diabetic state. Glucosuria was ascertained using Tes-tape strips (Eli Lilly, Indianapolis, Ind., USA) on the day of mating which took place one week after STZ injection. If a vaginal plug was found on the morning of the next day, this was considered the first day of pregnancy. Non-pregnant animals were mated again after a one week interval. After three negative matings, the animals were discarded from the experiments.

All the animals were killed on day five of pregnancy. The blood sugar was measured with glucose oxidase reagent strips (Glucopat, Menarini A, Firenze, Italy) and a reflectance photometer (Glucoscot, Menarini A, range 1-33 mmol/l). Blood samples were taken at the killing time by cutting the tip of the animal's tail. Diabetic animals with glycaemia below $11 \mathrm{mmol} / \mathrm{l}$ were excluded from the experiment.

In another set of experiments, subdiabetogenic doses of STZ were tested: $25 \mathrm{mg} / \mathrm{kg}$ and $35 \mathrm{mg} / \mathrm{kg}$. The results were compared with a new control group.

\section{Embryo collection}

Uterine horns were flushed with $0.5 \mathrm{ml}$ of pre-warmed Ham F 10 medium (Gibco 041-01550) to which $146 \mathrm{mg} / \mathrm{L}$ L-glutamine (Merck 289, Darmstadt, FRG), 100,000 IU/l penicillin and $100 \mathrm{mg} / \mathrm{l} \mathrm{streptomycin}$
(Flow Laboratories, Rickmansworth Herts, England) were added. The embryos were collected and transferred into fresh Ham F 10 incubation medium. The embryos were first observed by phase-contrast microscopy (Olympus IMT-2, Olympus Optical Co, Tokyo, Japan) for their morphological aspects and then prepared for the nuclei counting.

\section{Nuclei counting}

The method of Tarkowski described for the mouse [27] was adapted and allowed us to evaluate the number of nuclei in the structures. This technique used a hypotonic treatment (trisodium citrate $0.9 \%$, $15 \mathrm{~min}$ ) to disrupt the cell membrane, followed by the addition of a few drops of freshly prepared fixative mixture (acetic acid/ethanol: $1 / 3$ volume/volume). The nuclei were stained with a $4 \%$ Giemsa solution (Merck) in sodium phosphate buffer ( $\mathrm{pH} 6.8,0.005 \mathrm{~mol} / \mathrm{l}$ ). Stained nuclei were counted under oil immersion (100x) (Olympus $\mathrm{BH} / 2$, Olympus Optical Co).

\section{Statistical analysis}

Results are given as mean \pm SD. Statistical comparisons between groups were performed using the two tailed unpaired Student's $t$-test or the chi-squared test $\left(\chi^{2}\right)$. The level for a statistically significant difference was set at $p<0.05$.

\section{Results}

Embryo analysis in day five pregnant diabetic rats (50 mg STZ/kg)

Embryonic stages of structures collected from uterine horns on day five of pregnancy are shown in Table 1 . The blastocyst stage was defined as an embryo with a blastocoele cavity, while the morula stage was an embryo without visible blastocoele; the other structures were fragmented or degenerated. The two experimental groups were studied simultaneously to avoid any interference from seasonal variations. The diabetic group presented a significantly lower rate of blastocysts, a threefold higher

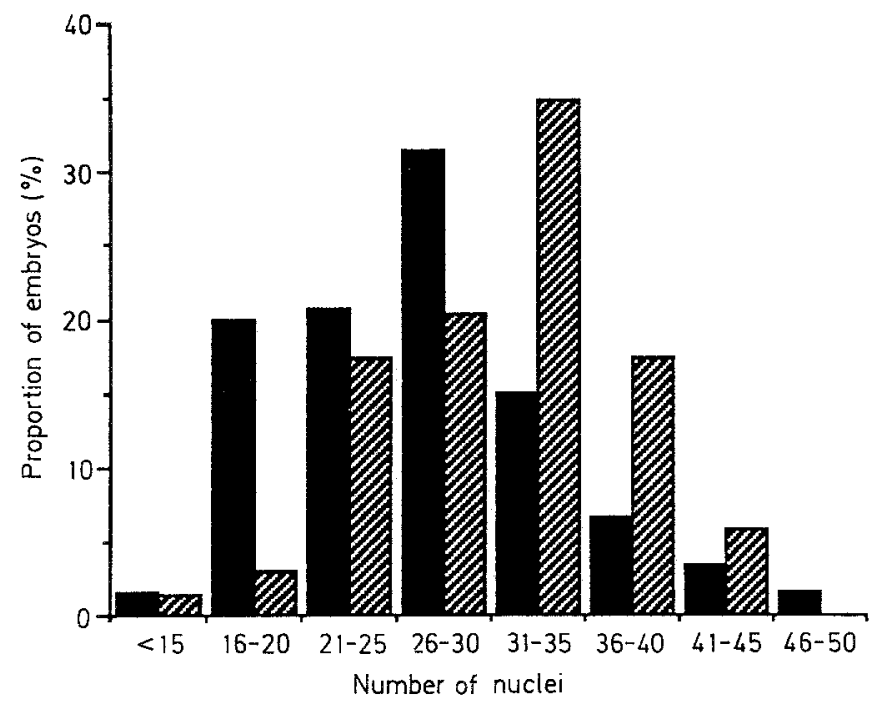

Fig. 1. Distribution of nuclei counting per blastocyst in day five pregnant control (hatched bars) and diabetic rats (black bars) 
Table 3. Nuclei counting of blastocysts from day five pregnant control and diabetic rats ( $50 \mathrm{mg}$ streptozotocin $/ \mathrm{kg}$ ) (mean $\pm \mathrm{SD}$ )

\begin{tabular}{llc}
\hline & Control rats & Diabetic rats \\
\hline Number of rats & 22 & 26 \\
Number of stained & 69 & 121 \\
blastocysts & $31 \pm 6.1$ & $26.9 \pm 7.3^{\text {a }}$ \\
Number of nuclei/blastocyst &
\end{tabular}

Table 4. Morphological stages of embryos from day five pregnant control and subdiabetic rats

\begin{tabular}{|c|c|c|c|}
\hline & \multirow[t]{2}{*}{ Control rats } & \multicolumn{2}{|l|}{ Subdiabetic rats } \\
\hline & & $25 \mathrm{mg} \mathrm{STZ} / \mathrm{kg}$ & $35 \mathrm{mg} \mathrm{STZ} / \mathrm{kg}$ \\
\hline Number of rats & 15 & 9 & 10 \\
\hline Glycaemia (mmol/l) & $5.61 \pm 1.21$ & $5.3 \pm 1.4$ & $12.65 \pm 7.1^{b}$ \\
\hline Number of structures & 130 & 69 & 75 \\
\hline$\%$ of blastocysts & 91.5 & 85.5 & $77.3^{\mathrm{a}}$ \\
\hline$\%$ of morulae & 7.7 & 10.1 & $22.7^{\mathrm{c}}$ \\
\hline$\%$ of others & 0.77 & 4.35 & 0 \\
\hline
\end{tabular}

Table 5. Nuclei counting of blastocysts from day five pregnant control and subdiabetic rats (mean \pm SD)

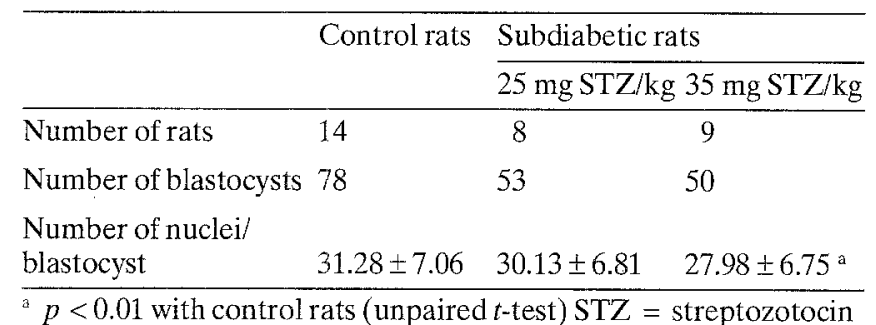

rate of morulae and no statistical difference for the other structures, compared to the control group. To avoid any skewing of these results, due to a possible litter effect, the data were further analysed on an individual basis. The number of total structures per rat was slightly although not significantly lower in the diabetic group. However, there was a significant decrease of blastocysts and a significant increase of morulae per rat in this group (Table 2). The distribution of nuclei per blastocyst in the diabetic group was shifted to the left when compared to the control group (Fig. 1). The highest proportion of embryos from the diabetic group had 26 to 30 nuclei while the control group had 31 to 36 . The mean number of nuclei per blastocyst was significantly lower in the diabetic compared to the control group $p<0.001$ (Table 3).

\section{Embryo analysis in day five pregnant subdiabetic rats (25 $\mathrm{mg}$ and $35 \mathrm{mg} S T \mathrm{Z} / \mathrm{kg}$ )}

Table 4 shows the morphological study of embryos collected from the two subdiabetic groups and a new control group. Mean glycaemia was similar in the control group and the group treated with $25 \mathrm{mg} \mathrm{STZ} / \mathrm{kg}$, whereas there was a significant increase in the group injected with $35 \mathrm{mg}$ STZ/kg when compared to the two other groups. The proportions of the embryonic stages were similar in the con-

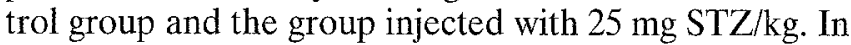
contrast, the group treated with $35 \mathrm{mg} \mathrm{STZ/kg}$ presented a significantly $p<0.05$ lower rate of blastocysts, and a threefold higher rate of morulae than the control group. The increased rate of morulae in the group treated with $35 \mathrm{mg} \mathrm{STZ} / \mathrm{kg}$ was at the limit of significance when compared to the group treated with $25 \mathrm{mg} \mathrm{STZ} / \mathrm{kg}$.

The control group and the group injected with $25 \mathrm{mg}$ $\mathrm{STZ} / \mathrm{kg}$ had similar mean numbers of nuclei per blastocyst, while there was a significant decrease in the group treated with $35 \mathrm{mg} \mathrm{STZ} / \mathrm{kg}$ when compared to the control group $p<0.01$ (Table 5).

\section{Discussion}

Experimental diabetes in rodents has been shown to impair fetal development [8-10]. "In vivo" [10] and "in vitro" $[8,11]$ studies have drawn attention onto the early postimplantation period, when incipient organogenesis appeared to be highly sensitive to the teratogenic agents. The present work, however, clearly shows that preimplantation development is also impaired in embryos of pregestational diabetic rats. Hence, embryos recovered from day five pregnant diabetic rats were less mature (higher proportion of morula stages at the expenses of blastocyst stages), and less developed (fewer nuclei in blastocysts) than embryos from day five pregnant normal rats. Although this observation is at variance with data reported in a strain of spontaneously diabetic Chinese hamsters in which no effect of maternal diabetes could be found before implantation [20], recent "in vitro" $[21,22]$ and "in vivo" $[23,24]$ experiments in rats and mice did suggest that the preimplanted embryo could be affected by the diabetic state of the mother. Hence Diamond et al. [23] showed that two-cell embryos from superovulating diabetic mice demonstrated an impaired development in vitro. Although normal development was restored by insulin treatment initiated before ovulation and mating took place, the potential teratogenic role of gonadotropin treatment for superovulation induction [28] remains a subject for concern in interpreting the reported data [23].

In a previous study, we showed in unstimulated, spontaneously ovulating diabetic rats, a $20 \%$ lower rate of implantation sites, compared to control animals [24]. The link between this observation and the data reported in the present work cannot be ascertained at the present time. One hypothesis could be an overall developmental delay, leading to delayed implantation, occurring normally on day six, in diabetic rats. However, in our previous work [24), we observed no increased rate of implantation on day seven, suggesting that the decreased number of implantation sites on day 6 was not due to a simple delay, but was indeed the consequence of a decreased number of implantable structures. Although damaged blastocysts are still able to implant, and may eventually enter a restorative phase of growth and morphogenesis, the potentiality of implantation and embryogenesis of such blastocysts is, 
however, decreased, depending on the relative loss of embryonic cells inside the inner cell mass [29]. Hence, delayed development, as observed here, could mask impaired development in specific subclasses of embryonic cells. Further work is underway to analyse this possibility [30]. The underlying mechanisms leading to impaired embryonic development during the preimplantation period also need further studies. Metabolic factors like ketone bodies impaired the development of preimplanted mouse embryos "in vitro", mainly in the presence of high levels of glucose [21]. Serum from diabetic subjects also impaired preimplanted mouse embryo development [22]. In the hamster, glucose can inhibit the "in vitro" development of 8-cell embryos [31]. The link between these observations and the present data is only speculative. Disturbed fuel availability has been implicated as a potentially teratogenic factor in postimplantation studies [8-14]. Similarly, one might speculate that lack or excess of specific fuels like glucose, might depress the energy supply to the developing preimplanted embryo, depending on its actual requirements [32]. The embryo indeed shifts from pyruvate and lactate to glucose during the preimplantation period, around the time of blastulation, depending on the animal species [32-34].

Another line of speculation could be the deleterious effect of glucose on DNA function and cell-cycle traversal, which was described recently in cultured human endothelial cells $[35,36]$, which, like preimplanted embryos [33], are insulin independent for glucose entry. No data are, however, available at present to sustain such a mechanism in embryonic cells.

Whatever the underlying mechanisms could be, we should not overlook that the disturbing factor(s) appear to be almost fully operative in subdiabetic rats, whose glycaemia has risen only twice above the control levels. Indeed, both morphological retardation and lower blastocyst cell number were encountered in the group of rats injected with only $35 \mathrm{mg} / \mathrm{kg}$ of STZ. A dose effect of STZ was observed for diabetes induction from $25 \mathrm{mg} / \mathrm{kg}$ (no effect on glycaemia) to $50 \mathrm{mg} / \mathrm{kg}$ (highest blood glucose levels). No such dose effect was observed for embryo impairment: no effect at $25 \mathrm{mg} / \mathrm{kg}$; near maximal effect at $35 \mathrm{mg} / \mathrm{kg}$. STZ is rapidly eliminated after its administration to the living animal [37], and should not influence embryo development one to three weeks later. It has indeed been shown that congenital malformations observed in STZ induced diabetic rats could be largely prevented by correct insulin treatment [10], making a direct effect of STZ itself unlikely. Although such an effect on the preovulatory follicle cannot formally be excluded, the absence of a dose-response effect of STZ on preimplanted embryos, as well as the absence of a time relationship between STZ injection and the fertilization process leading to impaired embryo development (from one to three weeks later) (unpublished observation), make this eventuality very unlikely. Impaired embryo development is coincidental with diabetes induction, and near maximal effect occurs at mildly elevated glucose levels.

In conclusion, our present data clearly show that maternal diabetes even of relatively mild degree, is able to impair embryo development during the preimplantation period. Caution should be taken at the present time to link these early effects with the potential teratogenicity of the diabetic state. The data, however, draw attention to the deleterious events which might to some extent precipitate the disturbed organogenesis.

The clinical implication of this finding might be twofold. Firstly, the diabetes linked embryotoxicity might be present without profound metabolic disturbances. Secondly, embryotoxicity could be anticipated in the preimplantation period i. e., even before the missed menses. Under such a hypothesis, the recently described lack of relation of increased malformation rates to glycaemic control during organogenesis [2] could be explained by inappropriate diabetic control, being either too late or not strictly adhered to, in view of the time and the diabetic stage at which deleterious effects on the developing embryo may occur.

Acknowledgements. We thank the Fonds de la Recherche Scientifique Médicale of Belgium for financial support (Grant $n^{\circ}$ $3 / 4590 / 88)$

\section{References}

1. Pedersen J (1977) The pregnant diabetic and her newborn, 2nd edn. Munksgaard, Copenhagen, pp 1-280

2. Mills JL, Knopp RH, Simpson JL, Jovanovic-Peterson L, Metzger BE, Holmes LB, Aarons JH, Brown Z, Reed GF, Bieber FR, Van Allen M, Holzman I, Ober C, Peterson CM, Withiam MJ, Duckles A, Mueller-Heubach E, Polk BF (1988) Lack of relation of increased malformation rates in infants of diabetic mothers to glycemic control during organogenesis. N Engl J Med 318: 671676

3. Mills JL, Simpson JL, Driscoll SG, Jovanovic-Peterson L, Van Allen M, A arons JH, Metzger B, Bieber FR, Knopp RH, Holmes LB, Peterson CM, Withiam-Wilson M, Brown Z, Ober C, Harley E, Macpherson TA, Duckles A, Mueller-Heubach E (1988) Incidence of spontaneous abortion among normal women and insulin-dependent diabetic women whose pregnancies were identified within 21 days of conception. N Engl J Med 319: 1617-1623

4. Kalter H (1987) Diabetes and spontaneous abortion: a historical review. Am J Obstet Gynecol 156: 1243-1253

5. Dicker D, Feldberg D, Samuel N, Yeshaya A, Karp M, Goldman JA (1988) Spontaneous abortion in patients with insulin-dependent diabetes mellitus. The effect of preconceptional diabetic control. Am J Obstet Gynecol 158: 1161-1164

6. Pedersen JF, Mølsted-Pedersen L (1981) Early growth delay detected by ultrasound marks increased risk for congenital malformation in diabetic pregnancy. Br Med J 283: 269-271

7. Spiers PS (1982) Does growth retardation predispose the fetus to congenital malformation? Lancet I: 312-314

8. Freinkel N (1988) Diabetic embryopathy and fuel-mediated organ teratogenesis: lessons from animal models. Horm Metab Res 20: 463-475

9. Eriksson UJ (1984) Congenital malformations in diabetic animal models - a review. Diab Res 1: 56-66

10. Eriksson RSM, Thunberg L, Eriksson U (1989) Effects of interrupted insulin treatment on fetal outcome of pregnant diabetic rats. Diabetes 38: 764-772

11. Sadler TW, Hunter ES, Wynn RE, Phillips LS (1989) Evidence for multifactorial origin of diabetes-induced embryopathies. Diabetes 38: 70-74

12. Akazawa S, Akazawa M, Hashimoto M, Yamaguchi Y, Kuriya N, Toyama K, Ueda Y, Nakanishi T, Mori T, Miyake S, Nagataki S (1987) Effects of hypoglycaemia on early embryogenesis in rat embryo organ culture. Diabetologia 30: 791-796 
13. Ellington SK (1987) Development of rat embryos cultured in glucose-deficient media. Diabetes 36: 1372-1378

14. Buchanan TA, Freinkel N (1988) Fuel-mediated teratogenesis: symmetric growth retardation in the rat fetus at term after a circumscribed exposure to $\mathrm{D}$-mannose during organogenesis. Am J Obstet Gynecol 158: 663-669

15. Travers JP, Pratten MK, Beck F (1989) Effects of low-insulin levels on rat embryonic growth and development. Diabetes 38 : $773-778$

16. Biggers JD, Borland RM (1976) Physiological aspects of growth and development of the preimplantation mammalian embryo. Ann Rev Physiol 38: 95-119

17. Biggers JD, Bell JE, Benos DJ (1988) Mammalian blastocyst: transport functions in a developing epithelium. Am $J$ Physiol 255: C 419-432

18. Iannaccone PM, Bossert NL, Connelly CS (1987) Disruption of embryonic and fetal development due to preimplantation chemical insults: a critical review. Am J Obstet Gynecol 157: 476-484

19. Spielman H, Eibs HG (1978) Recent progress in teratology. A survey of methods for the study of drug actions during the preimplantation period. Drug Res 28: $1733-1742$

20. Funaki K. Mikamo K (1983) Developmental-stage-dependent teratogenic effects of maternal spontaneous diabetes in the Chinese hamster. Diabetes 32: 637-643

21. Zusman I, Yaffe P, Ornoy A (1987) Effect of metabolic factors in the diabetic state on the in vitro development of preimplantation mouse embryos. Teratology 35: 77-85

22. Zusman I, Yaffe P, Ornoy A (1989) Effects of human diabetic serum on the in vitro development of mouse preimplantation embryos. Teratology 39: 581-589

23. Diamond MP, Moley KH, Pellicer A, Vaughn WK, Decherney AH (1989) Effects of streptozotocin- and alloxan-induced diabetes mellitus on mouse follicular and early embryo development. J Reprod Fert 86: 1-10

24. De Hertogh R, Vanderheyden I, Glorieux B, Ekka E (1989) Oestrogen and progestogen receptors in endometrium and myometrium at the time of blastocyst implantation in pregnant diabetic rats. Diabetologia 32: 568-572

25. Ekka E, Vanderheyden I, De Hertogh R (1981) Oestrogen receptors and oestrogen-induced protein synthesis in the uterus of diabetic rats. Diabetologia 20: 578-582

26. De Hertogh R, Ekka E, Vanderheyden I (1982) Estrogen receptor and stimulation of uterine protein synthesis in ovari- ectomized diabetic rats infused with $17 \beta$-estradiol. Endocrinology 110: 741-748

27. Tarkowski AK (1966) An air-drying method for chromosome preparations from mouse eggs. Cytogenetics 5:394-400

28. Sakai N, Endo A (1987) Potential teratogenicity of gonadotropin treatment for ovulation induction in the mouse offspring. Teratology 36: 229-233

29. Tam PPL (1988) Postimplantation development of mitomycin Ctreated mouse blastocysts. Teratology 37: 205-212

30. De Hertogh R, Vercheval M, Pampfer S, Vanderheyden I, De Bernardi P, Michiels B (1989) Experimental diabetes interferes with the early development of rat embryo in the pre-implantation period. Diabetologia 32: $480 \mathrm{~A}$ (Abstract)

31. Seshagiri PB, Bavister BD (1989) Glucose inhibits development of hamster 8-cell embryos in vitro. Biol Reprod 40: 599-606

32. Seshagiri PB, Bavister BD (1989) Phosphate is required for inhibition by glucose of development of hamster 8-cell embryos in vitro. Biol Reprod 40: 607-614

33. Gardner DK, Leese HJ (1988) The role of glucose and pyruvate transport in regulating nutrient utilization by preimplantation mouse embryos. Development 104: 423-429

34. Genos DJ, Balaban RS (1983) Energy metabolism of preimplantation mammalian blastocysts. Am J Physiol 245: C40-45

35. Lorenzi M, Montisano DF, Toledo S, Barrieux A (1986) High glucose induces DNA damage in cultured human endothelial cells. J Clin Invest 77: 322-325

36. Lorenzi M, Nordberg JA, Toledo S (1987) High glucose prolongs cell-cycle traversal of cultured human endothelial cells. Diabetes 36: 1261-1267

37. Karunanayake EH, Hearse DJ, Mellows G (1976) Streptozotocin: its excretion and metabolism in the rat. Diabetologia 12: $483-488$

Received: 11 August 1989

and in revised form: 14 November 1989

Dr. R. De Hertogh

Physiology of Human Reproduction Research Unit

University of Louvain School of Medicine

Av. E. Mounier 53 U.C.L. 5330

B-1200 Brussels

Belgium 